\title{
Lietuvos bibliotekų kompiuterizavimas: bibliotekų susivienijimas - politika ir problemos
}

Vladas BULAVAS

Letuvos nacionalinè Martyno Mažyydo biblioteka, Gedimino pr. 51, 2600 Vilnius, e-mail: v.bula@rc./rs.It

Vakaru šaliu biblioteku problemos, pavèlavusios ne mažiau kaip dvidesimt metu, iškilo ir Baltijos šaliu bibliotekoms. Ǐ ju viena svarbiausiu - modemios kompiuteinés technologijos diegimas visu lygiu bibliotekose.

Vienok atsilikusi technologiné bazé, lyginant su Vak Y̌alimis, netrukdé šios srities entuziastams pradéti pla nuoti, projektuoti bei diegti pirmasias automatizuotas bibiotekines sistemas.

Devintojo dě̌m nèje bibliotekoje iš esmès susidomèta biblioteky kompiu erizavimu. Pasitellos Centrines statistikos valdybos Skaciavimo centro specialistus buvo atliti projeltavimo darpai ir isanalizuotos bibliotekos technologiniy procesy kompiuterizavimo galimybes. Buvo numatyta papauti ines statistikos valdybos Kolektyinio paudojimo ciavimo centro vieningos sistemos kompiuterius ir isteigt Lietuvos nacionalinejje bibliotekoje abonentini punkt déjus eksperimentinj elektroninio katalogo formavima susidurta su CDS/ISIS programinès jrangos trikumais, formacijos perdavimo ir jos gavimo techniniais sunhmais. Tuo metu pasirode personalinigi kompiuterigi priverté suabejoti pasirinktos automatizacijos perspeltyvomis. Po $1990 \mathrm{~m}$. Lietuvos nacionalinè Martyno Mažyydo biblioteka jsipijo pirmuosius IBM suderinamus personalnius kompiuterius, pradejjo kurti automatizuotas darbo vietas bei kompiuterini tinkla. Vietoje naudoto bibliografiniam aprašui MEKOF (Международны едины коммуникативныя формат) pradètas naudoti UNIMARC formatas. $1993 \mathrm{~m}$. pradèta rengti ir jidiegta programin ranga kompiuteriniam bibliotekos katalogui ELKAT, $1995 \mathrm{~m}$. - UNIKAT, leidžianti kataloguoti visu rüšiu dokumentus UNIMARC formatu. Nuo $1993 \mathrm{~m}$. bibliotekoje pradétas einamojo spaudos srauto katalogavimas, ir juo metu bibliotekos kompiuteriniame kataloge jau yta beveik 80 tukst. bibliografiniy irašl. Taip pat pradeta dieg dalykiniy rubriky duomeny baze, leidziant pagerint in formacijos paieskos kompiuteriniame kataloge kokybę quasluma. Kuriama autorizuoty iraš baze UNIMARC/ Athorities formatu.

(1) program nę jirangą ir kiti bibliotekos padaliniai pradéjo kurti vie tines bibliografiniu irašu duomenų bazes: Vadovybés informavimo skynus kuria Seimui skirta periodines spaudos

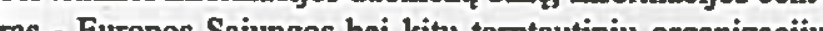

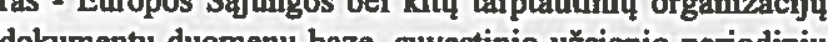
eidini lyos 1995 "Biplo lip pat su des analins infor

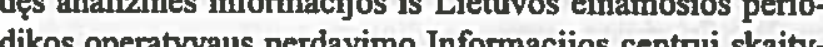

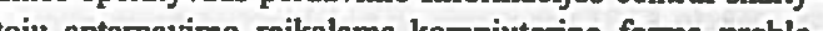
ming 120 tikst a Déimtajame desim tmetyje kitose Lie

ietuvos biblioteDerion Vilniaus panaudojo Norvegijos doyanteram katalogui sudaryti mašina ir adaptavo programine iranga BIBLa medicinos akademijos ir Lietuvos moksly akademijos bibliotekos isigijo latviu parengta programine irangr ALSE ir pritaikẻ ja savo reikméms. Kauno technologijos ir Vytauto Diďziojo universitety bibliotekos isigijo ir naudoja DANTEK fimos parengt programine irang ir naudoja Lietuvos technikos biblioteka katalogavimui ir informacijos paicškai naudoja CDS/ISIS. Kitos bibliotekos bando kurti savas programines irangas (Vilniaus technikos universiteto, Lietuvos policijos akademijos, Vilnisus pedagoginio universiteto) arba taiko Lietuvos nacionalinés Martyno Mažvydo bibliotekos parengta UNIKAT programine iranga.

Lietuvos biblioteku kompiuteriniuose kataloguose 1995 m. pabajgoje buvo sukaupta per 285 tükst. bibliografinity irašu, iš ju Lietuvos nacionalinèje Martyno Mažzydo bibliotekoje - 195 tükst.

Nemažai Lietuvos bibliotekı isigijo ir naudoja dalykinį rubriky duomenu bazę (Kauno technologijos universiteto, Vytauto Didžiojo universiteto, Vilniaus pedagoginio universiteto, Klajpedos taiversiteto, Lietavos polieijos aka-

Kitose Baltijos Šalyse taip pat pradéti biblioteku automatizavimo darbai. Entuziazmas bei Vakarı saliu parama 
sudaré salygas pasiekti క̌ioje srityje nemažy laimèjimu. Lietuvoje, kaip ir kitose Baltijos šalyse, isikürus Atviros visuomenés fondams, buvo pradétos remti ši šaliu biblioteku plètros programos. Skandinavijos Salys kai kurioms bibliotekoms pateiké techninę bei programinę iranga. JAV Kongresas, remdamas Baltijos šali cijos tamybas, dali kompiuterines technikos padovanojo Lietuvos, Latvijos ir Estijos nacionalinems bibliotekoms. 1992 m. NORDINFO skyré lés̆ kompiuteriniu tinklụ kûrimo pradžiai nacionalinèse bibliotekose. Ši parama be pačiu biblioteku léšos sudarè sąlygas vykdyti automatizavimo darbus, pavyzdžiui, Rygos universitete sukurta programiné iranga ALISE pritaikyta UKMARC formatui. Nuo $1992 \mathrm{~m}$. minétos bibliotekos kataloge ivesta per 80 tükst. iražn. Nors ALISE ir apima pagrindinius bibliotekos techming mingai diegiama kitose aštuoniose Latvijos bei Estijo

Latvijos moksly akademijos biblioteka isigijo prancū z4 Sistemą LIBER, kuri, deja, kelia bibliotekai daug rūpesči, nes yra nepaslanki ir nepritaikyta darbui keliomis tekos kompiuterinis tinklas bei visateksčily dokumenty duomeny bazé, idiegtas CD-ROM tinklas.

Estijos, idiegtas CD-ROM tinklas. pradèta Suomijos viešuju biblioteky naudojamo sékmingai nio paketo KIRI adaptacija, ir todél biblioteka šiugramiieško geresnés sistemos.

Latvijos vacionaline biblioteka isigijo VTLS svarbiausius modulius ir pradéjo diegti kompiutcrizuota katalogavima, serialiniy leidiniy apskaita bei skaitytoju bibliotekinị ir informacini aprüpinim

Lietuvos, kaip ir kity Baltijos Saliy, biblioteky kompiuterizavimo pagrindiné kliūtis - lèšy trükumas. Nepaisant reklamos, programa Lietuva-2000 nefinansuojama Lietuvos integrali biblioteku informacijos sistema (LIBIS), kaip sudétinè jos dalis, valstybinés paramos iki šiol praktiškai negavo (tik $1995 \mathrm{~m}$, pabaigoje Kulturos ministerija skyré Lietuvos nacionalinei Martyno Mažyydo bibliotekai ésy LIBIS projektavimu

Pagrindinis lešy Kaltinis bibliotekoms kompiuterizuoti Lietuvoje buvo biblioteky vidinés léšs bei ivairüs visuoAtre fondai ir uzsicnio valstybiu parama.

Atviros Lietuvos fondas 1993 m. pradéjo remti biblioje prograje je programoje pagrindinis demesys buvo skitas teisiniu liniy biblioteky integrotos infor dokmenty ir moksmui. Minetoje programoje pagrindinés Lietuvos sukirinés, universitety bei kity auksuju molyluty ir 5 moksliLietuvos miesty viežosios bibliotekos, remiamos Atviros Lietuvos fondo, ketino:

1. Sukurti ir idiegti integruota informacine moksliniy biblioteky sistemą bibliografinés ir faltografinés informacijos kompiuterizuotam užsakymui, tvarkymui, paieškai bei šu biblioteky skaitytoju aptarnavimui ir biblioteku valdymut
2. Sukurti ir idiegti integruoła nacionalinés bibliograjos rengimo ir nacionalinés spaudos centralizuoto katalogavimo sistemq

3. Sukurti nacionaliness bibliografijos duomeny baze kompiuterine forma bei CD-ROM;

4. Sukurti suvestinius Lietuvos mokslinèse bibliotekose gaunamu užsienio knygu, periodiniu bei tẹstiniu leidiniy katalogus kompiuterine ir spausdinta forma.

Siems darbams atlikti buvo apskaiziuotos reikalingos lèšos sudariusios per $5 \mathrm{mln}$. JAV doleriu iš ju $2 \mathrm{mln}$. JAV doleriy techninei jrangai, $2 \mathrm{mln}$. JAY doleriy progr. JAV jrangai, $1 \mathrm{mln}$. doleriy sistemy adaptavimui personin mokymui. Be to, buvo manoma kad sistemos projsonalo mas kainuotı apie 25 tükst. JAV doleriy.

Dar buvo numatyta, kad teisiniams bei nomatyviniam Lietuvos bibliotekininkystès dokumentams (standartams, taisyklèms, formatams, rubrikynams, terminu žodymams, UDK lentelèms mokslinèms bibliotekoms ir kt) pareng, ir išleisti reikès apie $0,5 \mathrm{mln}$. JAV doleriy.

Dabar, skaiziuodami LIBIS projekto realizavimo išlaidas, gauname panašius skaičius (apie $21,9 \mathrm{mln}$. litu) Gaila, kad G. Soroso fondas, $1994 \mathrm{~m}$. skyres nemazai le $\xi_{1}$ bibliotekinems programoms automatizacijos srityje remti $1995 \mathrm{~m}$. susikoncentravo savo paties informaciniu struktaru Baltijos salyse organizavimui, o mokstiniu bibliotek automatizavimui šose šalyse lèš beveik nebeskyré. Taciau Lietuvos specialistai, remiami Atviros Lietuvos for do, spéjo parengti pagrindinius planuotus normatyvinius dokumentus: UNIMARC for ins pertimą i lietuviu kalba dalykiniı rubriky kataloga, išversti i l lietuviu kalbą ISBD. Taip pat išleista studija "Lietuvos integrali biblioteky informacijos sistema" lietuviy kalba bei "Lithuanian Integrated Library Information System"3 angly kalba. Lietuvos nacionalinès Martyno Mažyydo bibliotekos lesomis rengiami bibliotekninkystès, bibliografijos bei leidybos termin Zodynai, verciamos ir adaptuojamos Lietuvai UDK lentelés mokslinéms bibliotekoms, rengiamo katalogavimo taisykjès. Visa tai yra geras pagrindas toliau

1993 m. liepos 8 d. biblioteky kompiuterizacijai paspartinti isteigtas Lietuvos moksliniy biblioteky susivienithas (LMBS)4. Pagrindinis LMBS tikslas - paspartint - diegti bibbliotekose modernią informacinę technologi-

- gerinti priéjimą prie katalogy bei kartotekł, greitinti ir plésti pirminiu dokumenty bibliotekose ir per TBA nau-

- stiprinti kooperavima ir darbo pasidalijimą tarp Lic-

- koordinuoti biblioteky komplektavima ir kitas veiklos sritis

- taikyti naujas technologijas vertingy dolumenty fonSutarta.

maciné sistema nacionaliné moksliniy biblioteky infor- ruota sistema, besiremianti darbo pasidalijimu katalogavimo bei bibliografiniy duomen baaly him srityse centr.

Taip pat buvo suformuluoti LIBIS reikalavimai:

sistema turi büti atvira, jos resursai prieinami vi siems skaitytojams ir institucijoms;

sistema turi vadovautis tarptautiniais normatyviniais dokumentais (UNIMARC, ISBD, ISO/CCL, ISO raidži tinkiniai ir t.t.)

turi būti garantuotas tarptautinis komunikatyvinio formato naudojimas įrašu importui-eksportui;

- sistema turi naudoti standartinius telefono ir viešojo audojimo duomenu perdavimo tinklus.

LMBS narés isipareigojo kooperuotis, rengiant programinę bei techninę sistemos ịranga

Integrali sistema pradedama kurti nuo suvestinio katalogo, kaip pagrindinio posistemio, kuris bus paskirstyto katalogavimo pagrindu. Suvestinio katalogo informacijos masyvą sudarys valstybinés bei užsienio spaudos bibliog rafiniai ir autorizuoti iră̌sai.

Numatomi kiti integralios sistemos posistemiai:

retrospektyviosios konversijos posistemis, iskaitant ma išleidimą;

OPAC (dialoginis viešojo naudojimo katalogas) skaitytojams Lietuvoje ir užsienyje;

- komplektavimo, skaitytoju aptamavimo, TBA ir kt. posistemiai.

Sutarti pasirašiusios 8 bibliotekos nutaré neriboti LMBS apimties ir leisti $i$ sistema jungtis kitoms Lietuvos mokslinéms bibliotekoms bei informacijos jstaigoms. Buvo pabrèžta, kad sutarti pasirašiusios LMBS narés turès lengvaty naudojantis informaciniais ir techniniais sutartyje dalyvaujančiı bibliotekụ bei informacijos ịstaigu resursais.

Dabar LMBS sudaro jau 17 biblioteky ir artimiausiu metu jis dar gali pasipildyti.

Svarbiausias LMBS uždavinys - LIBIS projektavimo organizavimas.

Lietuvos nacionalinés Martyno Mažvydo bibliotekos hiciatyva buvo isleistas kulturos ministro $1995 \mathrm{~m}$. rugsejo 25 d. isakymas Nr. 314, kuriuo nutarta kurti šalyje LIBIS, nustatytas jos kữimo eilišsumas. Biblioteka buvo pareigota organizuoti ir koordinuoti LIBIS kürima. Kartu siuo dokumentu Kultüros ministerija, vykdydama Lietuvos Respublikos biblioteku istatymo nuostatas dèl vieningo Respublikos biblioteky fondo (20 str.) ir valstybiniy biblioteky veiklos koordinavimo (27 str. 9 skirsnis), jipareigojo skirti lěš LIBIS projektavimui bei diegimui Kultüros ministerijos reguliavimo sferai priklausančiose bibliotekose (Nacionalineje ir apskričị bei rajonı̨ viešosiose bibliotekose).

Vykdant minétą kultūros ministro isakymą, buvo paskirtas LIBIS vadovas ir sudaryta LIBIS valdyba, atsiskai-
Sīrimo darbus, pateikianti LMBS tvirtinti tik strateginius

LIBIS $1995 \mathrm{~m}$, spalio 2 d. paskelbtą projektuotojo kon10j gro $1995 \mathrm{~m}$.

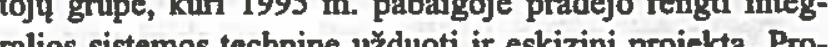
jekto technine užduotis aprobuota LIBIS valdyboje, sudeninta su Ryšiu ir informatikos bei Kultüros ministerijomis. $1996 \mathrm{~m}$ knvo $1 \mathrm{~d}$. buvo paskelbeas tarptautinis konkursas LIBIS techninei bei programinei irangai. Dalyvauti konhurse norijo 11 fimu ir bendroviu iš ju tokios pasaulyje kurse norejo 11 fimc ir bendrovit, is ju tokios pasaulyjo zk. Pasiülymai buvo pateikti tiek kompleksiniam LIBIS airimi tiek is astini prograxinei ar techninei irangai, sistemai idiegti ar palaikyti.

LIBIS projekta numatoma realizuoti trimis etapais:

I etapas - 16-oje bibliotekuq: Lietuvos nacionalineje Martyno Mažvydo bibliotekoje, 14-oje moksliniu biblioteky ir Kauno apskrities viešojoje bibliotekoje - LMBS nariy - sukuriama bei idiegiama automatizuota biblioteky informacijos sistema (ABIS) bei LIBIS operatorinis centras (1997-1998 m.)

- II etapas - 9-ose Lietuvos apskričiu (ǐsskyrus Kauno, kuri yra I etapo) viešosiose bibliotekose ir 7-ose likusiose aukštuju mokyklu bibliotekose sukuriama bei idiegiama ABIS ir itraukiama i LIBIS (1997-1999 m.).

- III etapas - 44-ose Lietuvos rajony ir miestu savivaldybiy bei kurortu viešosiose bibliotekose sukuriama bei idiegiama ABIS ir itraukiama i LIBIS (1997- $2000 \mathrm{~m}$.) Artimiausias LMBS uždavinys yra parinkti ir suderinti tolesnę LIBIS kūrimo ir diegimo strategija. Tuo tikslu pirmiausia reikia:

1. Rasti LiBIS finansavimo saltinius, is kuniy galimi 1.1. Lietuvos Vyriausybes programa biblioteky kompleksiniam modemizavimui arba tix kompiuterizavimui, 1.2. Tarptautiniai fondai, remiantys bibliotekų kompiuterizavima, tokie kaip A.W. Mellono ar G. Soroso.

1.3. Tarptautines organizacijos ir jy remiamos programos, tokios kaip UNESCO, Europos Sajunga ir Europos Taryba;

1.4. Informacijos firmos, norincios j̇sitvirtinti Lietuvoje bei kitose Baltijos šalyse ir galinčios suteikti lengvatiniu kreditu LIBIS kūrimui;

1.5. Fimos, lizingo büdu galinčios pateikti LIBIS tech-

ninę iranga;
1.6. Żinybu, universitety bei savarankišsk bibliotek léšos ir $\mathrm{k}$

2. ABIS diegti bibliotekose turi būti sukurtos specialios grupés, o Lietuvoje - specializuota organizacija, atsakinga už LIBIS diegima, pritaikyma, personalo mokyma duomeny apdorojima, technikos ir programinés irangos palaiky al Tali be LIBIS diegiancia uzsienio fira a jeigu toka butty pasivoje , a ti aptarnati Aiske voje degtir apun 
antras variantas, nes toje tarnyboje galèty būti sutelkti gerai apmokami Lietuvos specialistai. Tajp bưtu taupomas laikas ir léšos. Jau dabar Lietưoje cogzistuoju daupoju užsienio kompiuteriniu kompaniju dukterinés ara atstovaujančios firmos (MOTOROLA, IBM, HP ir kt). Personalui mokyti LIBIS kürèjai turi skirti ypatinga demesji. Bibliotekos patyré, kad be kvalifikuoto personga kompiuterizavimo procesas gali büti sukompromituotas iš pat pradžių. Lietuvoje bei kitose Baltijos šalyse, kur kompiuteriai pasirodé palyginti velai, bibliotekose dirba nemažai vyresnés kartos specialistu, kurie studijuodami bibliotekininkystę, neturéjo sąlygu susipažinti su moderniomis kompiuterinèmis technologijomis. Diegiant kompiuterius bibliotekose, dažnai šiems darbuotojams reikia nugaletti tam tikrą psichologini barjerz, nepasitikejjima savo jègomis, baimę prarasti darbą ir pan. Bibliotekos adaptacijos naujoms darbo salygoms periodas kartais užtrunka kelet̨q metų. Todèl, dar prieš jisigyjant pirmuosius kompiuterius, bibliotekos administracija turi pasirüpinti, personalo pradiniu mokymu darbui su kompiuteriais. Jaunesnioji specialistu karta mokoma jei ne vidurineje, tai aukštojoje mokykloje. Vèliau jie mokomi diegti konkrečias bibliotekines sistemas. Tad sutartyje su firma numatomos léšs specialiems kursams bei stažuotèms.

Bibliotekiniy procesy kompiuterizavimui reikalingas tinkamas biblioteku pasirengimas. Dažniausiai tai susije su bibliotekiniy procesy ir net biblioteky struktüros pertrat bei reorganizavimu. ABIS kurti, diegti ir eksploatuoti butojas secialus personalas, turi buti direktoriaus pavaduojal sukurtas ABIS padalterizacija, turi būtì darbuotojas, atsakingas už ABIS die-

LIBIS bendrasistemiams uždaviniams spręsti Lietuvo nacionalinés Martyno Mažvydo bibliotekoje ir Kauno technologijos universiteto Skaiciavimo centre bus jkurti spe 7y dap ty dara, ty. drome i suvestini LIBIS kataloga ivedoperajo koms konvertoojant ju katales takininkauti biblioteorganizuojant TBA Jeslauges i kompiuterinę forma menty duomenu bazes, Jau dabar tu, reikia išspresti dus. teisiu ir kitus LIBIS organizacinius bei teis, and mus.

Prasidèjo moksliniu biblioteku konsorciumy kūrimas $1994 \mathrm{~m}$. Estijoje ir I fondo planams Baltijos salyse, nutarta stiprinti Baltijos saliu moksliniy biblioteky bendradarbiavimg cen Baltijos to katalogavimo, Baltijos šalyse gaunamos Vakary literatüros suvestinin liografijos bei kitose srityse. Pradéta kalbèti apíc bendrus pripcipus, kuriant ABIS atskirose bibliotekose bei Baltijos salyse, tartasi dél biblioteky valdymo principu modernizaTaline konsorciention biblioteky protokiumai bei Latvijos biblioteku darbo grupé pasiraše

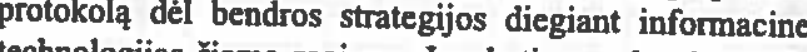
the regione. Juo ketinama kurti Baltijos ir stei ir steigt koordinacinę valdyba. UNIMARC formatas priimtas kaip mainy formatas šiame regione. Informacines Pa dalys bus:

- kiekvienos dalyvaujančios bibliotekos dialoginis katalogas ir Şaliu suvestiniai dialoginiai katalogai (cinamieji ir retrospektyvieji);

Baltijos šaliu suvestinis dialoginis katalogas;

duomenu bankas (einamosios produkcijos bibliografiniy liogrefijos) platinimas ir retrospektyviosios bibCD-ROM;

- duomenu baziu sistema, kartu su katalogy bei duomeny baziu valdymo mazgais;

komplektavimo, serialini leidinin koutrolis, skatytoju aptarnavimo, TBA, visatcksch dokumenty, sendymo, saugojimo, ir kt. sudétinés dalys.

Baltijos Saliy moksliniy biblioteky bendradarbiavim kompiuterizacijos srityje skatina ne tik senos bendradarbiavimo tradicijos, bet ir noras bendromis pastangoargreičiau integruotis i Vakaru biblioteku tinklus, isitraukt jau egzistuojanti darbo pasidalijimo tarp bibliotrenkti kooperavimo procesus (OCLC, PICA ir kt). Bendromis programomis, jungiančiomis Baltijos biblioteku büsimo konsorciumo bibliotekas, tikimasi didesnio tarptautiniu fon dy dèmesio bei paramos. A.W. Mellono foudo payedim $1995 \mathrm{~m}$. atlikta Baltijos moksliniy biblioteky ir apskim ekonomines ir politinés padéties studija teikio ir apskrita Sio fondo bibliotekiniy programy eksperto prof. R.E Quandt bei kitu žymiu Vakaru bibliotekininkystés specia listy kartu su Baltijos ir Šiaurés šaliu politikais dalyvavimas NORDINFO organizuotame seminare Taline 1996 m. balandżio $25-26 \mathrm{~d}$. biblioteky politikos klausimais, nyçau, turés didelès jitakos Baltijos šaliu bibliotekụ autonatizavimui bei modernizavimui.

' Quandt R.E. Report on Baltics. - Princeton, NJ, April 17, 1995. - 99 p. - Rankrastis

Bulavas V., Gudauskas $R$, Varnient $R$. Lietuvos integral Bulavas V., Varniené R. Litbuanian - Vintiuss, 1994. - 50 p.

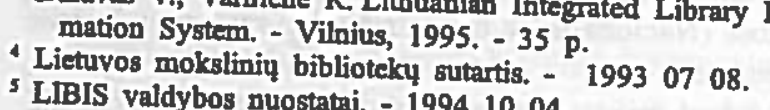

Summary

Computerization of Lithuanian Libraries: Library Consortium - Politics and Problems

Vladas BULAVAS

The problems of the libraries of Westem countries, hough rather belated - almost after 20 years, started f ing the librares of the Baltic cor 20 s. The most signiThent are he inglemes of libray systems and relued to the realization of this task difficulties.

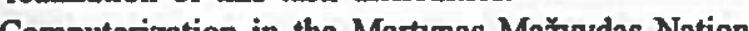

Compulerization in the Martyas Mažydas National Library of Lithuania commenced at the beginning of the CDSTSIS Con to be not cfoctive In 1993, the softrare ELTAT hes been created at he librory, which enabled to catalogue the con collo Since the tenth decade, other Lithuanian libraries also tarted promoting computerization. Vilnius University Library, Kaunas Academy of Medicine Library, Library of the Kaunas University of Technology, Vytautas Magnus University Library, after acquiring different software began to create their owm online catalogues.

Aiming to pursue their objectives in the field of automation and to achieve co-ordination in acquisition, five major Lithuanian libraries signed a co-operative agree- ment for consolidating their efforts to accelerate automaon this agreement, on July 8, 1993 a Consor-

The main goal of the Consortium became the creation of the Lithuanian Integrated Library Information System (LIBIS) It was agreed that the system would be inplemented as an integrated and co-pperative system based an a labour sharing approach in the spheres of cataloin

The establistent of the Consotium of the Lithugian Research Libraries resulted in the agreement between the libraries for the necessity of using the interational standards and following the structural design of the LIBIS project The project was prepared by the programmers the specialized technical group of the Kaumes University of Technology, who won the competitive contest and also, employing the joint efforts of the specialists of the National Library.

The project specifies the organizational-functional structure of LIBIS, its juncture in the INTERNET, better information supply of the users, exchange of bibliographic databases with other countries. 